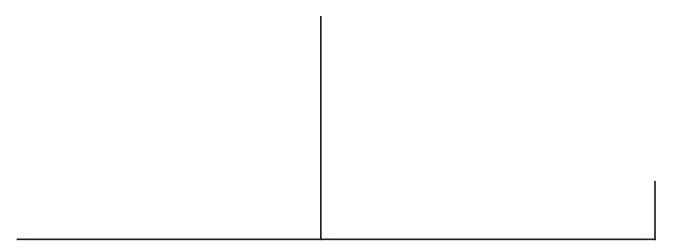

\title{
De uma psicopatologia geral a uma psicopatologia fundamental. Nota sobre a noção de paradigma*
}

Pierre Fédida

Este artigo examina a seguinte questão: existiria uma abordagem especializada do humano que, sem ser nem uma psicologia nem a psiquiatria, tenha os meios metodológicos de um projeto de observar e descrever os distúrbios psíquicos e compreender seu acontecimento fenomenal singular no cerne da generalidade da experiência?

A questão se acha colocada desde 1910 por Karl Jaspers nos trabalhos que precedem a publicação, em 1913, de sua Psicopatologia Geral.

A partir daí, o problema ao qual nos encontraríamos confrontados é o da condição fenomenológica da psicopatologia, ou seja, a vontade de não fazê-la resultar e depender da psicologia. E se a psiquiatria é, há um tempo relativamente longo, um terreno de observação e de pesquisa racional de classificações, é preciso constatar que suas práticas empíricas foram, há muito, consideradas impotentes para conduzir à constituição de uma psicopatologia.

Dessa forma, o autor é levado a argumentar que seria, então, conveniente pensar o projeto de uma psicopatologia fundamental como um projeto de natureza intercientífica, em que a epistemologia comparativa dos modelos e de seu funcionamento teórico-crítico desempenharia o papel determinante de uma consciência de seu limite de operatividade e de sua aptidão a transformarem-se uns aos outros.

* Este texto foi originalmente publicado em Crise et contre-transfert de Pierre Fédida, Paris, PUF, 1992, pp. 287-301. Traduzido por Monica Seincman. 


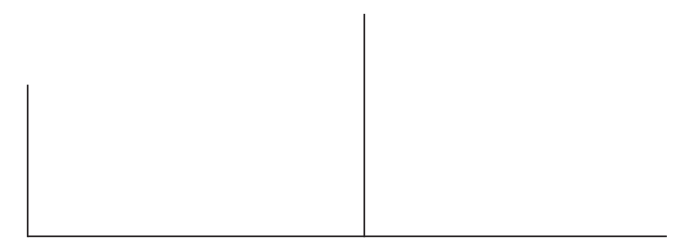

Existiria uma abordagem especializada do humano que, sem ser nem uma psicologia nem a psiquiatria, tenha os meios metodológicos de um projeto de observar e de descrever os distúrbios psíquicos e compreender seu acontecimento fenomenal singular no cerne da generalidade das experiências? A questão se acha colocada desde 1910 por Karl Jaspers nos trabalhos que precedem a publicação, em 1913, de seu importante tratado intitulado Allgemeine Psychopathologie (Springer Verlag) e traduzido para o francês sob o título Psychopathologie générale (Psicopatologia geral) (Paris, Alcan, 1933). Em 1913, na Alemanha, a idéia de uma "psicopatologia geral" não dependia necessariamente de um projeto fenomenológico. Se Arthur Tatossian estiver certo ao se perguntar se, "em certo sentido, teria havido uma psicopatologia que não a alemã" , seria justo observar que a fenomenologia não ocupa, neste momento, na Psicopatologia geral de Jaspers, o lugar que se poderia esperar em sua (esta se pretende, acima de tudo, uma "metodologia sistemática" face à confusão reinante na psiquiatria da época) e que está, no entanto, em um tipo de afinidade intrínseca necessária com uma psicopatologia que não mais se pode conceber como uma psicologia patológica e nem mesmo como uma psicologia do patológico.

1. A. Tatossian e S. Giudicelli. "De la phénoménologie de Jaspers 'au retour à Husserl'. L'anthropologie compréhensive de Zurt et Kuhlenkampff", in Confrontations psychiatriques, 11, 1973, pp. 127-161. 
O problema ao qual nos encontraríamos assim confrontados, é o da condição fenomenológica da psicopatologia, cuja orientação antropológica já aparece em Kant e até em Husserl, ou seja, a vontade de não fazê-la resultar e depender da psicologia. E se a psiquiatria é, há um tempo relativamente longo, um terreno de observação e de pesquisa racional de classificações, é preciso constatar que suas práticas empíricas foram, há muito, consideradas impotentes para conduzir à constituição de uma psicopatologia.

Como o observam A. Tatossian e S. Giudicelli, segundo K. Jaspers em sua Autobiografia filosófica, o projeto da Psicopatologia geral era, antes de tudo, o esclarecimento conceitual do "que se sabe, como se sabe e do que não se sabe" (Jaspers). Já que "todo homem doente é, como qualquer homem, inesgotável" e, enquanto totalidade, "além de qualquer objetivabilidade conceitual", ele não poderia se originar da funcionalidade das noções sintéticas da psicopatologia científica como as de constituição, de biografia causal, de unidade nosológica. Sempre se considerou - e Lacan não escapa a esta interpretação da obra de Karl Jaspers - que a Psicopatologia geral oferecia ao método de compreensão a vantagem prevalente da abordagem dos distúrbios psíquicos sobre a descrição positiva destes através das classes, dos gêneros e das espécies, através das noções comparativas com as categorias psicológicas do homem são. A "psicopatologia geral" de Karl Jaspers faz apelo, aqui, à compreensão (à "relação compreensiva") somente para creditá-la de uma capacidade de limitação de conhecimento: "O conhecimento causal nunca encontra seus limites... a compreensão os encontra em todos os lugares" (K. Jaspers, Psicopatologia geral). Poder-se-ia ver em Jaspers uma verdadeira obstinação em manter a relação de compreensão unicamente ao nível do discernimento crítico e clínico da consciência sistemática, principalmente em oposição a Freud, a quem Jaspers reprova a introdução causal de relações pseudocompreensivas - o inconsciente (a Psicopatologia da vida cotidiana é de 1901). Hoje, com W. Blankenburg e A. Tatossian, perguntar-nosíamos se tal obstinação tem valor de intransigência fenomenológica. Retenhamos, no entanto, que a psicopatologia geral de Karl Jaspers, pouco rigorosa fenomenologicamente, tem o mérito de contribuir historicamente para a constituição de uma antropologia fenomenológica em psicopatologia.

Seguindo Dilthey (1894), Jaspers individualiza o método de compreensão genérica da sucessão dos vividos, privilégio da psico(pato)logia, que partilha o método de explicação causal indutiva com as ciências da natureza: "Em muitos casos, compreendemos como o psíquico nasce com evidência do psíquico... quando o homem atacado fica com raiva, quando o amante enganado se torna ciumento... a evidência da compreensão genética é algo último... experimentamos uma evidência imediata que não podemos aplicar a nada mais" (Psicopatologia geral). Mas a evidência de uma relação compreensível que não tem "a força de 


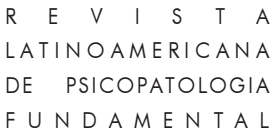

convicção de uma demonstração causal empírica" não prova sua realidade em um caso específico, que pede verificação objetiva. Uma verificação positiva, mesmo que repetida, não acrescenta nada à evidência em questão, assim como uma verificação negativa não diminui (a ação favorecedora do outono para os suicídios é objetivamente falsa, mas continua evidente). Mais ainda, pode-se imaginar que um poeta apresenta, de maneira convincente, relações compreensíveis que, no entanto, nunca aconteceram. Elas são irreais, mas possuem sua evidência geral no sentido ideal-típico (A. Tatossian e S. Giudicelli, De la phénoménologie de Jaspers "au retour à Husserl”, op. cit., p. 130).

Esta idéia de "evidência geral no sentido ideal-típico" é mencionada por Tatossian e Giudicelli a partir da contribuição de Jaspers em "Kausale und 'vertändliche' Zusammenhänge zwischen Schicksal und Psychose bei der Dementia Praecox (Schizophrenie)" (1913). A ligação do causal e do compreensível é aqui solicitada com relação à esquizofrenia, e a serviço da distinção entre as idéias delirantes e as idéias paradelirantes. Tatossian e Giudicelli prosseguem:

O tema da compreensão genérica aparece, na verdade, desde 1910, para distinguir os delírios de ciúme compreensíveis a partir da personalidade e da biografia, como desenvolvimento de personalidade, dos que não são, e introduzem uma solução de continuidade, os processos, dos quais nada podemos dizer, nem mesmo que se baseiam sobre uma lesão cerebral. A oposição, bastante comum no meio psiquiátrico em que trabalhava Jaspers, ainda que proveniente, na Psicopatologia geral, da abordagem biográfica mais do que da nosologia, acaba, na prática, por tornar a incompreensibilidade genética o critério dos delírios verdadeiros, processuais e, essencialmente esquizofrênicos; ela tem seu eco na fenomenologia dos vividos com a distinção das "idéias delirantes verdadeiras" e das "idéias paradelirantes" (wahnhafte Ideen), deriváveis de outros vividos. Mas o incompreensível nas primeiras não é seu conteúdo, freqüentemente acessível à compreensão, mas o próprio fato de seu aparecimento (...). Assim como "aí, onde verdadeiramente há delírio, a compreensão a partir do caráter cessa e, aí onde se pode compreender, não há delírio". (Kurt Schneider) (Op. cit., p. 130)

Neste cruzamento - talvez ao mesmo tempo possível e impossível - entre a psicopatologia geral de Karl Jaspers e a fenomenologia husserliana, colocamse questões decisivas sobre a generalidade e a fundamentalidade na abordagem especializada da psicopatologia. Não há dúvida de que no início do século - ao mesmo tempo com Freud e com Husserl e cada um a seu modo -, uma psicopatologia geral tende a constituir-se a partir de uma atitude crítica contrária à psicologia "acadêmica" e à psiquiatria semiológica e nosológica (principalmente de inspiração kraepelineana). No entanto, não nos apressemos em supor que a 
psicopatologia geral encontraria seu método na fenomenologia ou na psicanálise. E também não nos precipitemos em opor psicopatologia geral (fenomenológica) à nosologia psiquiátrica. Como o mostra um recente trabalho de Tatossian ("Classificação psiquiátrica e fenomenologia"), discutido por R. Jouvent ("Uma clínica para pensar. Uma clínica para agir") $)^{2}$ " "a fenomenologia mantém com a classificação psiquiátrica relações paradoxais". E acrescenta:

... a pesquisa fenomenológica em vez de propor, como a psicanálise, novas entidades, não evita desenvolver-se no quadro daquelas da clínica psiquiátrica tradicional: esquizofrenia, mania, melancolia..., mesmo que freqüentemente ela desloque sua definição. Green viu nisto a prova de uma certa inconsistência da fenomenologia que reintroduzia em seu próprio seio o conceito de doença sob formas dissimuladas. É necessário, antes, evocar que ela não encontra em sua problemática própria a noção de doença mental, e encontra aí a matéria para a reflexão sobre as modalidades de descoberta e a natureza exata das entidades reconhecidas pela clínica e, portanto, sobre a natureza mesma desta. (p. 272)

Observando o parentesco do tipo psicopatológico com a essência fenomenológica, Tatossian nos convida a ver nos conceitos desta razão das essências (ou tipos) matrizes fenomenológicas da organização dos dados recolhidos pela clínica.

Em certo sentido, a generalidade pesquisada pela psicopatologia, no espírito de uma racionalidade dos fenômenos-limite que ela observa, não pode advir senão de um procedimento fenomenológico decididamente husserliano (portanto, eidético): esta generalidade conduz ao esclarecimento de "modelos prototípicos" (cf. N. Cantor, citado por Tatossian) e, certamente, a uma razão de classificação, segundo uma lógica wittgensteiniana. Isto significa que a generalidade nomeada pela psicopatologia, enquanto uma disciplina distinta, é possível se a "razão classificatória" (para retomar aqui o título do belo livro de Patrick Tort [Aubier, 1989]) - cuja história é epistemologicamente rica de ensinamentos - trouxer a capacidade de engendramento de novos conceitos a partir de uma clínica fenomenológica das diferenças infinitas. E, a esse título, a clínica psicopatológica se autodesigna como uma leitura das operações semiológicas produzidas pelos processos de comunicação em certas situações específicas. Se não é completamente certo que a psicanálise participe desta clínica, por outro lado, nada contradiria a idéia de que estas operações semiológicas constitutivas da leitura dos processos (necessariamente inter-subjetivos) sejam, ao mesmo tempo, de ordem pragmática, cognitiva e empática. Tal hipótese, largamente ilustrada

2. A. Tatossian. "Classification psychiatrique et phénoménologie", in Revue internationale de psychopathologie, 2, 1990, pp. 271-289; R. Jouvent. "Une clinique pour penser. Une clinique pour agir". Comentário e resposta ao artigo de A. Tatossian, ibidem, pp. 291-295. 


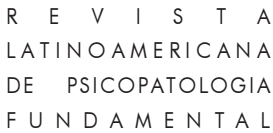

pelos trabalhos de Blankenburg, conduz, então, à compreensão das generalidades psicopatológicas em termos de eficacidade psicoterápica (cf. Blankenburg, "La signification de la phénoménologie pour la psychothérapie", in P. Fédida e J. Schotte, Psychiatrie et existence, Millon, 1991). Mas - para além da distinção entre conhecimento causal e limitação deste pela "relação de compreensão" que serve, em Jaspers, a uma teoria implícita da comunicação com o outro - qualquer constituição de uma psicopatologia geral através de uma clínica fenomenológica pressupõe, de algum modo, um princípio de fecundidade eidética dos "modelos prototípicos" assim evidenciados. Do ponto de vista psiquiátrico, tratar-se-ia, então, menos de saber se este doente responde à sintomatologia da psicose maníaco-depressiva ou da esquizofrenia, do que se um determinado distúrbio que ele apresenta comporta clinicamente - enquanto fenômeno - o poder de solicitar novas efetuações eidéticas de uma ou outra noção. Tais efetuações fariam parte do processo psicoterápico (mais particularmente "daseinanalítico") no sentido em que elas comportariam no praticante, em seu trabalho com o doente, a apresentação intersubjetiva das modalidades de ser e das operações (cognitivas, pragmáticas, relacionais) que, justamente, colocam-no em falta de comunicação. Não é por acaso que as noções husserlianas de presentação, representação e apresentação desempenham na literatura fenomenológica e existencial da psicopatologia um apelo tão determinante (cf. L. Binswanger, R. Kuhn, W. Blankenburg etc.).

A partir daí, a solução de facilitação seria desdobrar a oposição entre fenomenologia e psicanálise em psicopatologia geral e psicopatologia fundamental. A bem dizer, esta simplificação não é impossível se for estabelecido previamente que a psicanálise, em seu próprio desenvolvimento, está, com certeza, pouco interessada pelos progressos de uma psicopatologia geral e, por outro lado, que a racionalidade teórico-clínica de seu método não coordena necessariamente a explicação psicopatológica dos conceitos, modelos ou hipóteses teoricamente postos em operação por sua prática. Por exemplo, que valor teria para uma psicopatologia geral o enriquecimento teórico-clínico do narcisismo ou de certas formas de negativismo não esquizofrênicos, já que sua "modelização" - em estreita ligação com a situação psicanalítica e seus problemas técnicos só assume um alcance psicopatológico quando é de natureza metapsicológica? E se se tratasse aqui de justificar um tipo de "fundamentalismo" psicopatológico na e pela psicanálise, poder-se-ia legitimamente querer que tal exclusividade, com pretensão hegemônica, interessasse efetivamente a psicopatologia epistemologicamente implicada na psicanálise? E dentre estas questões - que realmente colocam o problema da psicopatologia psicanalítica, ou ainda, da condição, desta vez psicanalítica, de uma psicopatologia do cotidiano - não deixaria de ressaltar a interrogação primordial sobre a vocação de uma 
fundamentalidade em um campo tão mal definido e cujos objetos são também tão incertos quanto os que entram no projeto de uma psicopatologia? Nenhum psicanalista deixaria de dizer, hoje, que, se a psicanálise resolveu uma contradição científica, foi por ter decidido não mais se definir como uma psicopatologia. Então, por que colocar a este respeito a questão da condição de uma psicopatologia fundamental?

Sabe-se que qualquer insistência retórica na promoção de uma idéia faz, inevitavelmente, que se corra o risco destes programas ideológicos que escondem, na verdade, rivalidades de poder. Tais rivalidades não faltam, hoje, nem entre os psicanalistas nem fora deles. $\mathrm{O}$ problema que debatemos aqui ofereceria, sem nenhuma dúvida, uma destas questões que, de forma alguma, se formulam nos debates habituais e que também não se originam da controvérsia, mas que são difíceis de se ignorar com relação ao lugar da cura psicanalítica e das psicoterapias, à função do ensino da psicanálise independentemente da formação do psicanalista ou ainda a propósito das "pontes" entre neuropsicologia e psicanálise. Por não ser mencionada, a distinção entre psicopatologia geral e psicopatologia fundamental fica abolida no ideal de uma clínica psicopatológica mais refinada possível, considerando o homem em sua famosa totalidade. Na verdade, é sob esta luz que reaparece a esperança de uma prevalência fenomenológica ignorante de sua própria filosofia: sempre vestida com uma prática psicanalítica, esta clínica repousa sobre uma recusa da técnica da psicanálise e dos conceitos de transferência e resistência que são referenciais desta. E o que se pode nomear clínica em psicanálise deveria se desfazer dos preconceitos psico-estratégicos da famosa contratransferência geralmente concebida como uma consciência transubjetiva dos processos intersubjetivos. Seria suficiente, sem dúvida - mas isto não é nada! - compreender a clínica psicanalítica (e sua dimensão de psicopatologia) unicamente baseada na situação analítica e, assim, nas condições dos desvios que ela inevitavelmente produz, como o fracasso fecundo que opera. É que, na psicanálise, a "observação psicopatológica" é indissociável do invisível dispositivo ótico da situação e, portanto, da recepção das temporalidades transferenciais da fala plural do paciente. Poder-se-ia, inclusive, se interrogar sobre as condições segundo as quais tal observação da análise se modifica a ponto de se tornar observação do psicopatológico, ou seja, observação discursi$v a$ de um co-funcionamento, e até mesmo das disfunções. Seriam, certamente, estas disfunções que autorizariam um uso de tipo "cognitivo" de certas operações de compreensão de fenômenos de comunicação.

A questão não é tanto, hoje, a da "não-refutabilidade" (Karl Popper) da psicanálise e, sim, a transmissibilidade de seu discurso. Desde que os psicanalistas tomaram gosto por uma comunicação de seu pensamento frente a um público cultural mais ou menos indiferenciado (não exclusivamente "psicanalítico"), os 


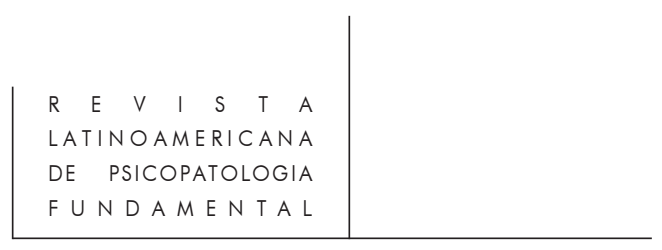

testemunhos clínicos que trazem tendem a se fazer exemplarmente ilustrativos e perderem, assim, seu valor de pertinência propriamente psicanalítico. Seja sob formas de observações desenvolvidas ou apenas de "seqüências" extraídas de uma sessão, o alcance demonstrativo que lhes é concedido não vale geralmente senão para um discurso de argumentação temática que participa, na verdade, de uma "nova teoria das paixões" e, assim, de uma psicopatologia geral - em suma, de inspiração bem fenomenológica. Desconsiderando o fato de que, certamente, as contribuições a esta teoria das paixões beneficiam incontestavelmente descobertas e achados advindos da colaboração contínua (e com freqüência intensa) entre o analista e seu paciente. Mas, no todo, a destinação "cultural" do discurso psicanalítico o desvia no sentido de uma presentação psicopatológica generalista de seus "modelos" e tende correlativamente a autorizar a reputação de uma clínica refinada dos processos psíquicos. Nestas condições, seria completamente abusivo pretender que a psicanálise fundamentalize os conceitos e os modelos da psicopatologia, a menos que seja necessário compreender, com isto, que uma tal "fundamentalização" pressupõe apenas o poder do patológico de esclarecer - por assim dizer pelo negativo - os processos ficticiamente normais. Mas, doravante, não basta mais lembrar que o sonho é uma psicose em pequenas doses, a cada noite, no homem normal ou ainda que a melancolia esclarece, em contrapartida, o fenômeno normal do luto, que deu, ele mesmo, acesso ao sentido libidinal da perda do objeto. A "dialética" do normal e do patológico na psicanálise certamente conduz a uma revisão - desta vez, bem fundamental - do que se chama psicopatológico e do estatuto teórico ficcional da hipótese (de natureza identificatória) da normalidade.

Face a representantes de uma outra especialidade diferente da sua, o psicanalista só pode sustentar um discurso cuja argumentação obedece a um regime modificado da racionalidade teórica em atividade em sua prática da cura. A modelização e formulações de hipóteses, as presentações de conceitos certamente formadas em sua atividade metapsicológica com os pacientes - devem refletir secundariamente e submeter-se, assim, a condições de comunicação "científica" que não são geralmente incluídas nos processos de pensamento durante a cura. Este regime modificado da racionalidade teórica pode, na verdade, concorrer a uma fundamentalização psicopatológica dos modelos e dos conceitos, se tal fundamentalização for tomada como uma contribuição da psicanálise à fundação intercientífica da psicopatologia. Hoje em dia, é justamente a isto que se assiste, graças a certas trocas entre psicanalistas e neurobiólogos ${ }^{3}$ ou ainda

3. D. Widlöcher. "Neurobiologie et psychanalyse. Les opérateurs de commutation", in Revue internationale de psychopathologie, 2, 1990, pp. 335-356; P. Fédida. "A propos de 1'article de Daniel Widlöcher", ibidem, pp. 357-364. 
especialistas de outras disciplinas (imunologistas, neurocognitivistas etc.). Seria, então, conveniente pensar o projeto de uma psicopatologia fundamental como um projeto de natureza intercientífica, em que a epistemologia comparativa dos modelos e de seu funcionamento teórico-crítico desempenharia o papel determinante de uma consciência de seu limite de operatividade e de sua aptidão a transformarem-se uns aos outros. Caso em que, o fundamental seria aqui um ideal de comunicação mais do que o objeto de uma esperança de "ciência unificada". Mas é, no entanto, verdade que uma tal comunicação dos psicanalistas - à condição de que sejam seriamente informados sobre as especialidades a que se dirigem - é possível apenas por redução da comunicação especificamente analítica que obedece, no que lhe diz respeito, a condições completamente diferentes que as pretendidas pela argumentação. Em uma palavra, é o que chamamos análise de supervisão o que regula estas condutas de transmissão, pelo menos ao nível da formação de uma comunidade psicanalítica. ${ }^{4}$

Poderia produzir diversos testemunhos pessoais para fundamentar esta questão. Darei apenas dois. Em vista de minha participação em um simpósio psicanalítico sobre Masoquismo e feminilidade, tinha como projeto elaborar algumas hipóteses sobre "o materno no fantasma masoquista e o corpo obsessivo". Escolhi centrar mais particularmente minha intervenção em torno da queixa de esterilidade, e, para fazê-lo, retomei minha anotações de trabalho escritas durante certos tratamentos já passados. Para mim tratava-se de submeter a meus colegas norte-americanos minhas próprias reflexões e, principalmente, minhas interrogações relativas à influência de fantasmas masoquistas que trazem neles o impossível luto da mãe (em todos os casos, a mãe morrera, quando a paciente era adolescente) e que garantiam, sob o modo de uma melancolia impossível, um sofrimento compulsivo que protegia de uma ameaça de aniquilação (na transferência) e, assim, de uma desintegração de identidade. Pude trazer, nessa comunicação, um material analítico extremamente preciso sobre o qual tentava basear minha hipótese da tentativa de regeneração de um auto-erotismo - sob condições transferenciais diversas, conforme o caso em questão (três casos de referência). Para uma das pacientes, cujo caso era evocado, tentei evidenciar a idéia de que a queixa melancólica da esterilidade em nome do desejo infantil visava, particularmente, personificar o psicanalista - sua presença sendo transferencialmente, ao mesmo tempo, a fonte do desejo insistente infantil (desejo edípico) e intrusão silenciosa no corpo, sob o modo paranóide de uma penetração invisível pela mãe. Como se, neste caso, fosse confiada à dor a conservação de uma identificação, os órgãos femininos devendo "definhar" e "se fechar" -

4. "La construction du cas", in Nouvelle revue de psychanalyse, 42, 1990, pp. 245-260. 


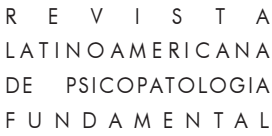

inclusive fisiologicamente - para que tal identificação melancólica protegesse da ameaça de desintegração que comportaria inevitavelmente a fecundação.

Posteriormente, quando se tratou de apresentar estas hipóteses diante de um público de ginecologistas que me pediam uma conferência sobre "a aproximação psicanalítica da questão da infertilidade", me foi, evidentemente, impossível tratar desta questão nos termos em que havia feito anteriormente entre os analistas. No entanto, não faltava nos especialistas da procriação um interesse muito vivo por tal "abordagem psicanalítica", ainda mais que a maioria deles se encontrava convencida do papel dos "fatores psíquicos" em vários casos de infertilidade. Minha exposição teve por objeto principal a evidenciação das modalidades corporais - neste caso clinicamente próximas à anorexia/bulimia de um funcionamento obsessivo observado durante as curas psicanalíticas, permitindo supor o papel desempenhado por uma "melancolia inibida".

Em uma outra situação (tratava-se de uma reflexão conduzida entre os imunólogos sobre a oportunidade de certas psicoterapias analíticas com pacientes soropositivos), a problemática em comum concernia a uma inter-avaliação das "ficções" da imunidade. Se o analista comunica junto a imunólogos tal modelo formado imaginariamente na escuta de seu paciente, pode experimentar logo o caráter hiper-subjetivo da ficção que se opera e hesitar submetê-la a especialistas que devem se colocar ao nível da objetividade racional dos modelos construídos. Ora, um trabalho em comum sobre os modelos - contrariamente a qualquer espera de nossa parte - não excluía de forma alguma a consideração do ficcional, inclusive em suas formas consideradas como as mais "hiper-subjetivas". E, no entanto, se a ficção entra em qualquer atividade metapsicológica de construção durante a cura analítica, é fato que o analista, de forma alguma, pode comunicar sua formação em imagens e em palavras. E é, no entanto, esta parte, que alimenta a fala da interpretação, que diríamos ser econômica e dinamicamente maior.

A noção de fundamentalidade em psicopatologia poderia, pois, conceberse, hoje, sob o título da intercientificidade dos objetos conceituais próprios para definir um campo que, doravante, não mais é delimitado por uma oposição em relação ao "normal". Neste sentido, certamente não seria falso dizer que $a$ psicopatologia fundamental não existe senão enquanto esta intercientificidade dos objetos a torna possível. Se esta hipótese é epistemologicamente válida, ela deveria levar a ver que os dados empíricos da psicologia (quase) comum bastam para fornecer as bases consensuais da compreensão: angústia(s), depressão(ões), inibição(ões), delírio(s), alucinação(ões) etc. designam "fenômenos" psicopatológicos suficientemente comuns para solicitar aqui e ali interrogações e pesquisas. No entanto, nenhuma destas palavras está em condições de designar os objetos inferidos e/ou construídos pelo neurofarmacólogo, pelo neuropsicólogo 
cognitivista, pelo lingüista, pelo filósofo ou pelo psicanalista. Uma teoria dos afetos - assim como, sob certos aspectos, pode ser concebida em um tratado como a Ética de Spinoza -, à condição de implicar em sua dedutividade conhecimento, ação e paixão, permitiria filosoficamente assegurar a sintaxe lógica das definições reflexivas. E, em nenhum caso, ela forneceria os objetos conceituais dos "afetos" indicados.

A denominação de um afeto e sua nomeação são, conviríamos com facilidade, um ato de linguagem totalmente determinante no curso do processo analítico. Esta denominação/nomeação pertence ao desenvolvimento do conhecimento endopsíquico e participa, assim, pelo trabalho analítico, da transformação da passividade, se não em atividade, pelo menos em potencialidades de fala, que vêm despertar as capacidades autópticas da língua. Não consideramos o suficiente esta função da regra associativa da análise. Associar livremente regra transferencial da confiança na fala - é deixar as palavras produzirem sua própria dessemantização e ressemantização, é também confiar à fala sua chance de traduzir as palavras pronunciadas de si para si mesmas. A fala transferencial - segundo as variações do silêncio que lhe são trazidas - procede como tradução, porque ela encontra na situação analítica sua liberdade de hesitar. Nestas condições, a noção freudiana de qualificação do afeto passa por um infinito (infinitesimal) quantitativo. A elaboração (Verarbeitung) do afeto se junta ao aumento do diferencial das ressonâncias.

Não é raro que a queixa da demanda - de alguma forma ligada à pessoa do destinatário - utilize as palavra depressão, cansaço, desespero, angústia, fracasso... nesta espera-desafio da resposta familiar inadequada ("Ele ou ela tem tudo o que é necessário para conseguir", "o que falta é a vontade", "não é saudável só pensar em si" etc.). Mas também não é raro que o paciente, no primeiro encontro, se pegue falando que está menos deprimido do que triste, que sua tristeza, já antiga, lhe parece, naquele momento, impedi-lo de chorar e o preserva, assim, de uma dor que teria liberado sua cólera; não é raro que ele chame de depressão um "cansaço de ser" em relação à presença contínua aterrorizante de sua esposa - como se este cansaço tivesse para ele uma doçura protetora etc. Esta seqüência tirada de uma primeira entrevista com um homem que acabara de tentar o suicídio, foi precedida por uma apresentação de si mesmo nos termos de um diagnóstico psiquiátrico, cuja semiologia formava, sem dúvida, os sinais miméticos de uma comunicação com o meio familiar. Se desenvolvêssemos esta observação, ficaríamos sabendo com o que se segue, que sob o efeito de certos antidepressivos, o paciente perde suas inibições de agir (ele começa a mudar muitas coisas em sua vida), mas se encontra impedido de falar na tranqüilidade associativa e anamnésica dos primeiros encontros. Ele se diz, aliás, curado e desvaloriza a "introspecção" em benefício da "vida ativa". 


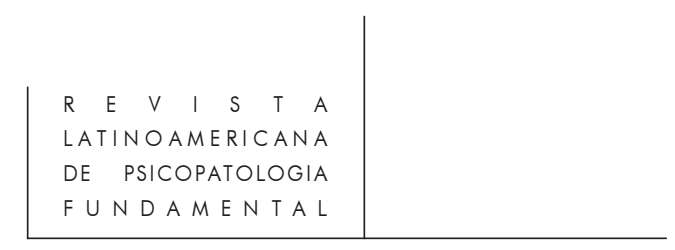

Esta breve observação dá a entrever que a depressão enquanto tal - qualquer que seja, no caso, seu conteúdo nosológico (o psiquiatra que o trata fala de depressão psicótica) - não poderia constituir o objeto conceitual de uma psicopatologia fundamental. A cura sintomática do paciente, graças à ação medicamentosa permitiria, por um lado, construir este objeto: o conhecimento da ação das moléculas químicas sobre as estruturas corticais e subcorticais detecta, de alguma maneira, o objeto psicopatológico. E, por outro - o do psicanalista -, a situação analítica instaurada quase que imediatamente oferece a possibilidade de construir um objeto não contraditório com o objeto constituído pela ação neurofarmacológica. Tratar-se-ia, ainda, de falar, tanto de um ponto de vista quanto do outro, de depressão? Provisoriamente sim. Mas o desconhecido químico e o desconhecido psicanalítico dissimulam, na verdade, pela construção de objetos conceituais, a pesquisa especulativa de modelos que se poderiam chamar "metapsicológicos".

Retornemos, ainda um instante, à atividade de nomeação/denominação do afeto. A alusão feita anteriormente a uma teoria dos afetos, cujo modelo pode ser encontrado na Ética de Spinoza, não será aqui mais amplamente desenvolvida. Assim como o observaram A.-J. Greimas e J. Fontanille (in Sémiotique des passions, Paris, Seuil, 1991), diferentemente da taxonomia cartesiana das paixões (arrolamento das paixões por dedução, classificação das seis paixões primitivas, depois das paixões “particulares"), a Ética procede por lógica sintática e por algoritmos: o rigor geométrico das definições dos afetos comporta uma lei geradora de extensão no procedimento da definição. Por exemplo, o ódio é "uma tristeza acompanhada da idéia de uma causa exterior". O que supõe que a definição da tristeza esclarece uma modalidade cognitivo-prática não empiricamente perceptível no "vivido" do ódio: é uma paixão "pela qual o espírito passa para uma perfeição mínima". É preciso, então, voltar ao que pode contrariar "a potência de agir de nosso corpo", sendo que é necessário pesquisá-lo naquilo que "contraria a potência de pensar de nosso espírito" (proposição XI). Mas em Spinoza tal procedimento gerador da definição está sintaticamente regulado por um desvelamento progressivo - de alguma forma autogerador - da lógica dos afetos na experiência que o espírito tem deles. A Ética é justamente, sob um certo aspecto, uma teoria dos afetos, se esta noção comportar o pensamento não apenas de uma transformação dos afetos em si mesmos, mas também desta transformação pelo poder de linguagem da denominação/nomeação.

Compreende-se já que uma psicopatologia fundamental - até então apreendida pelo projeto ideal de sua intercientificidade constituinte - não poderia satisfazer-se com a definição "acadêmica" em nome da interdisciplinaridade que lhe seria necessária! Se não é falso pretender que programaticamente a psicopatologia fundamental corresponda, hoje, à necessidade de fazer com que 
se troquem abordagens disciplinares heterogêneas em seus objetivos e em seus métodos, mas ao ocuparem-se de um campo consensualmente comum, chega inevitavelmente o momento - graças, principalmente, às aporias da comunicação intercientífica - em que a questão do fundamental traz consideráveis dificuldades não apenas epistemológicas, mas também quase ontológicas. Quando nos atemos às interrogações sobre as relações psique-soma ou mente-cérebro ou psíquicobiológico, ficamos na linha cautelosa das preliminares paralelistas. O paralelismo é uma falsa doutrina da desconfiança epistemológica que, na verdade, dissuade de ir adiante. Nada teria de abusivo o fato de a psicanálise ter, até hoje, pretendido conduzir só ela o projeto de uma psicopatologia fundamental, se, no entanto, os psicanalistas se mostrassem verdadeiramente curiosos e abertos aos avanços das ciências contemporâneas. Estas, apesar da aparente intransigência de que fazem prova em relação à cientificidade (e à não-cientificidade da psicanálise), estão muito mais atentas ao pensamento psicanalítico do que se crê. ${ }^{5}$

As racionalidades contemporâneas que mantêm as pesquisas - tanto em biologia molecular, em neuroquímica, quanto em lingüística ou em psicanálise fizeram deslocar os termos do célebre debate sobre a cientificidade. A ênfase dada ao aleatório, ao indefinido, ao indistinto favorece, incontestavelmente, uma mutação das ciências do homem - evidentemente, por pouco que estas renunciem progressivamente a seus dogmatismos ideológicos.

A fundamentalidade psicopatológica da psicanálise não se atém somente aos deslocamentos que ela efetua em relação à normalidade: a teoria psicanalítica metodológica e tecnicamente em ação na cura - recebe do sintoma, ao mesmo tempo, sua objeção e uma solicitação para transformar modelos que ela pressupõe no sentido não de uma nova generalização psicopatológica, mas sim no de sua universalização. Cada sintomatologia individual é singularmente uma teoria enigmática e literalmente infantil. Esta teoria construída pelo sujeito a serviço da defesa de sua identidade pessoal (qualquer sintoma é teoria autóctone de si) dispõe de uma auto-organização transferencial, cujo objeto intrapsíquico e/ou intracorporal é desconhecido do próprio sujeito. Em um sentido, então, a instauração de uma situação analítica vai, como se sabe, primeiramente reforçar a "crença" do paciente em sua teoria e, com bastante freqüência, aumentar a intensidade do sintoma. A transformabilidade dos modelos da teoria analítica é, pois, colocada à prova pelo paciente e, por mais que este esteja em condições de percebê-lo progressivamente, o sintoma se dará, então, as palavras de seu próprio pensamento. Será, então, possível colocar a idéia de que para cada paciente em análise, o sintoma desempenha o papel de um aparelho psíquico inédito que realiza, às vezes, sua própria ficção pelo uso que faz de

5. Apresentação da Revue internationale de psychopathologie, 1, 1990. 


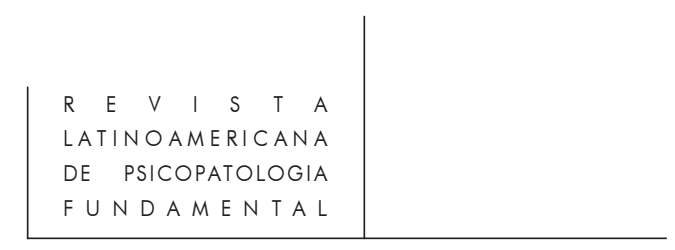

uma função de um órgão. Desta forma, cada paciente reúne, aqui, a utilização ficcional feita por Freud de todos os modelos - principalmente biológico ou óptico - para imaginar (ou seja, pensar teoricamente) o psíquico (inconsciente) entre o cérebro e os atos de consciência. Se a alma é aparelho (Seelenapparat), é porque o sonho forma teoria metapsicológica de um dispositivo óptico da memória do infantil e, ao mesmo tempo, da linguagem e do pensamento. Não é, pois, surpreendente que, sem desconhecer os procedimentos clínicos da generalidade psicopatológica (há uma nosografia psicanalítica), a psicanálise conceda fundamentalidade a objetos conceituais (recalcamento, clivagem, recusa, denegação, foraclusão, projeção... mas também luto, desamparo, perda, separação etc.) que dispõem de uma pré-discursividade teórica e se fundamentam no processo que os ignora.

Mas é também este um limite extremo que conviria, talvez, reconhecer na noção de psicopatologia na psicanálise.

\section{Resumos}

Este artículo examina la siguiente cuestión: ¿existiría un abordage especializado de lo humano que, sin ser ni una psicologia, ni una psiquiatria, tenga los medios metodológicos de un proyecto para observar y describir los disturbios psíquicos y comprender su acontecimiento fenomenal singular en el cerne de la generalidad de la experiencia?

La cuestión está colocada desde 1910 por Karl Jaspers en los trabajos que preceden la publicación, em 1913, de su Psicopatologia general.

A partir de ahí, el problema con el cual estábamos confrontados es el de la condición fenomenológica de la psicopatología, o sea, la voluntad de no hacerla resultar y depender de la psicologia. Y si la psiquiatría es, hace un tempo relativamente largo, un terreno de observación y de investigación racional de clasificaciones, es necesario constatar que sus prácticas empíricas fueron, hace mucho consideradas impotentis para conducir a la constitución de una psicopatología.

De este modo, el autor es llevado a argumentar que entonces sería conveniente pensar el proyecto de una psicopatología fundamental como un proyecto de naturaleza intercientífica, en que la epistemologia comparativa de los modelos y de su funcionamiento teórico-crítico desempeñaria el papel determinante de una conciencia de su limite de operatividad y de su capacidad para transformaren unos a los otros.

Cet article se penche la question suivante: existe-t-il un abordage spécialisé de l'humain qui, sans être une psychologie ni la psychiatrie, conserverait les moyens méthodologiques d'un projet d'observer et de décrire les troubles psychiques et 
comprendre le fait qu'ils aient lieu de manière phénoménale singulière au cour de la généralité de l'expérience?

Cette question a été posée par Karl Jaspers en 1910, dans les travaux qui ont précédé la publication de sa Psychopathologie Générale.

Le problème auquel nous nous verrions alors confrontés serait celui de la condition phénoménologique de la psychopathologie, c'est-à-dire de la volonté de ne pas la faire dériver ni dépendre de la psychologie. Et si la psychiatrie est, depuis assez longtemps, un terrain d'observation et de recherche rationnelle de classifications, il faut bien constater que ses pratiques empiriques ont été, depuis longtemps, considérées impotentes pour conduire à la constitution d'une psychopathologie.

Ainsi, l'auteur est amené à soutenir qu'il serait fort opportun de penser le projet d'une psychopathologie fondamentale comme un projet de nature interscientifique, dans lequel l'épistémologie comparative des modèles et de leur fonctionnement théorico-critique jouerait le rôle déterminant d'une conscience de leur limite opérationnelle et de leur aptitude à se transformer les uns les autres.

This papers looks upon the following question: is there any specialised approach of human beings that, not being a psychology nor psychiatry, could still both present methodological ways for an observation and description project of the psychic disturbances and understand their singular phenomenal occurrence in the heart of experience generality?

Such a question was asked by Karl Jaspers, in 1910, in the works preceding his publishing of General Psychopathology.

The problem to which we would thus be confronted is that of the phenomenological condition of psychopathology, i.e. the will not to make it result or depend on psychology. And if psychiatry has been, for quite a long time, a ground of observation and rational research on classifications, it is high time we asserted its empirical practice has long been considered impotent as for conducting the constitution of a psychopathology.

The author is thus driven to claim how convenient it would be to think the project of a fundamental psychopathology as an intersciences project, in which the comparative epistemology of models and their theoretical-critical functioning would play the determinant role of a consciousness of their operative limit and of their aptitude to transform each other. 